
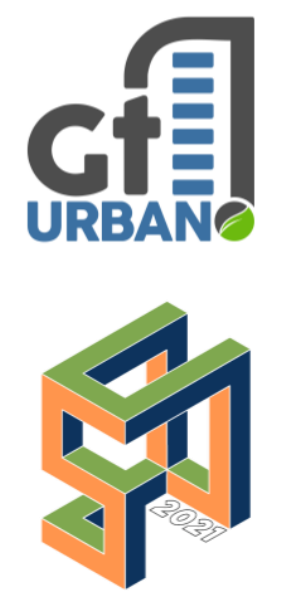

\section{SInGEURB}

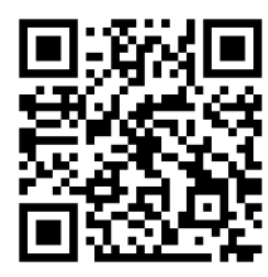

Como citar:

LEITÃO, Camila T.; SANTOS, Fernando $S$. T.; CARDELES, Vicenzo; SOUZA, Rafael L. T. Uma análise sobre $\mathrm{o}$ índice pluviométrico e as obras de drenagem na região do canal do mangue (RJ). In: III SIMPÓSIO NACIONAL DE GESTÃO E ENGENHARIA URBANA: SINGEURB, 2021, Maceió. Anais... Porto Alegre: ANTAC, 2021. p. 169-179. Disponível em: https://eventos.antac.o rg.br/index.php/singe urb/issue/view/14

\title{
Uma análise sobre o índice pluviométrico e as obras de drenagem na região do canal do mangue (RJ)
}

\author{
An analysis of the pluviometric index and \\ drainage works in the region of mangue \\ waterway $(\mathrm{RJ})$
}

Camila T. Leitão, Universidade Federal do Rio de Janeiro, camilatasca@poli.ufrj.br

Fernando S. T. Santos, Universidade Federal do Rio de Janeiro, fernandosantos@poli.ufrj.br

Vicenzo Cardeles, Universidade Federal do Rio de Janeiro, vicenzocardeles@poli.ufrj.br

Rafael L. T. Souza, Universidade Federal do Rio de Janeiro, rafael.souza@poli.ufrj.br

\section{RESUMO}

Eventos de chuvas intensas no Rio de Janeiro no período de Janeiro até Junho impactam a infraestrutura da cidade e a vida da população causando transtornos e perdas econômicas diversas. Após os desastres relacionados à chuvas de 2010 e 2011 foram iniciadas ações do Programa de Controle de Enchentes da Grande Tijuca (PCEGT), no âmbito do Plano Diretor de Manejo de Águas Pluviais (PDMAP), que implantaram um sistema de reservatórios de grande porte em praças disponíveis pela região da Bacia do Canal do Mangue, próximos aos principais rios, no intuito de retardar vazões de pico e evitar alagamentos. Foram estudados o regime de chuvas e de maré na região nos últimos 10 anos que comprovaram que não houve variação significativa e nem conjunção de fatores que explicasse a ocorrência de inundações após a construção dos "piscinões". A falta de resultados significativos na região suscita uma reflexão sobre outros fatores que devem ser endereçados daqui para frente a fim de se obter o retorno esperado em termos de eficácia para compensar os vultosos investimentos já realizados.

Palavras-chave: Canal do Mangue, Drenagem Urbana, Chuvas Intensas, Enchentes. \begin{abstract}
Heavy rain events taking place in Rio de Janeiro from January to June impacts the city infrastructure and the population routine, causing several inconveniences and several economic losses. After the 2010 and 2011 rain-related disasters, actions were taken initiated by the Greater Tijuca Flood Control Program (PCEGT), within the scope of the Rainwater Management Master Plan (PDMAP), which implemented a system of large reservoirs in squares available within the Canal do Mangue watershed, close to the main rivers in order to delay the peak flows and prevent flooding. The rainfall and tidal regime in the region over the past 10 years have been studied, which proved that there was no significant variation or a
\end{abstract}


combination of factors that could explain the occurrence of floods after the construction of the reservoirs. The lack of significant results in the region drives the reflection on other factors that must be addressed from now on in order to obtain the proper return in terms of effectiveness in compensation of the large investments already made.

Keywords: Canal do Mangue, Urban Drainage, Heavy Rain, Flood.

\section{INTRODUÇÃO}

Ao longo da história humana, grandes civilizações sempre estiveram ligadas ao mar, seja como ponto logístico de rotas mercantis, seja como fonte de recursos naturais. Atualmente, aproximadamente 3,2 bilhões de pessoas no mundo vivem dentro de uma faixa de $200 \mathrm{~km}$ a partir da costa dos países e, se expandirmos essa faixa para $400 \mathrm{~km}$, teremos quase $2 / 3$ da população mundial (JOYCE, CHANG, HARJI et al, 2017). Segundo OLBERT, COMER, NASH, et al (2017), tamanha concentração populacional se reflete também em concentração de um grande percentual do PIB mundial, com valores significativos em propriedades e infraestrutura.

Neste cenário, e a seguir dos desastres do Morro do Bumba, em abril de 2010, e da Região Serrana, em janeiro de 2011, foi lançado o Programa de Controle de Enchentes da Grande Tijuca (PCEGT), que objetivava implantar obras que melhorem a situação de inundações neste trecho da Bacia do Canal do Mangue, sendo as mais notórias os grandes reservatórios subterrâneos da Praça da Bandeira, da Praça Niterói e da Praça Varnhagen e o extravasor do Rio Joana.

Este artigo pretende consolidar dados históricos climatológicos e hidrológicos obtidos das diversas fontes oficiais, como o sistema Alerta Rio e a Marinha do Brasil (ALERTA RIO, 2020), sendo filtrados aqueles diretamente relacionados à Bacia do Canal do Mangue, que abrange diversos bairros do Centro e Zona Norte do Rio de Janeiro, com o intuito de elucidar algumas questões relevantes no regime de chuvas ao longo dos últimas 10 anos e o impacto que teve a implantação dos reservatórios no âmbito do PCEGT sobre os alagamentos da região, bem como uma análise geográfica do local e a interferência das marés na extensão da bacia.

\section{METODOLOGIA}

Foram analisados e tabulados dados de chuvas dos pluviômetros do sistema Alerta Rio que se encontram na região da Bacia do Canal do Mangue desde 2010 e os picos de chuvas foram identificados e comparados com datas de registros de inundações obtidos na imprensa e pela memória dos autores a fim de estabelecer os limiares de chuva que provocam cheias.

Após o estabelecimento do limiar de chuvas - ocorrerem durante o processo de evaporação da água nas zonas intertropicais do planeta, tal processo causa chuvas abundantes - que causam inundações na Bacia do Canal do Mangue, foram levantados dados sobre o nível das marés junto à Marinha do Brasil para tentar estabelecer uma correlação entre os fatores que possam ter contribuído para a ocorrência e uma análise de caracterização da região e de seus antigos problemas de inundações causados pelas chuvas. Por último, foram comparadas as propostas do PCEGT com os resultados efetivos. Além disso levantou-se teorias que possam explicar os resultados muito aquém dos esperados após os investimentos vultosos realizados nesta infraestrutura. 


\section{ESTUDO DE CASO}

A região da Bacia do Canal Mangue há muitas décadas é afetada por inundações decorrentes das chuvas, fossem elas moderadas (quando a intensidade é igual ou superior a $2,5 \mathrm{~mm} / \mathrm{h}$ mas inferior a $10 \mathrm{~mm} / \mathrm{h}$ ) ou fortes (quando a intensidade é igual ou superior a $10 \mathrm{~mm} / \mathrm{h}$ mas inferior a $50 \mathrm{~mm} / \mathrm{h}$ ). A partir de $2010 \mathrm{com}$ iminência da realização da Copa do Mundo em 2014 e Olimpíadas em 2016 o Município se submeteu a amenizar o problema que afetava diretamente a região que incluía Estádio do Maracanã, já que esse passou a apresentar inundações depois da reforma ocorrida para os Jogos Pan-Americanos de 2007. No Plano Diretor de Manejo de Águas Pluviais da Cidade do Rio de Janeiro do ano de 2010 foi incluída uma proposta para equacionar o problema das cheias, o plano incluía a construção de uma série de reservatórios de detenção, reforço de galerias subterrâneas, restituição do curso do rio Joana a sua foz natural e a derivação do Rio Maracanã para o Rio Joana.

A partir de 2013 os reservatórios projetados começaram a ser finalizados, sendo o da Praça da Bandeira $\left(18.000 \mathrm{~m}^{3}\right)$ o primeiro, Praça Niterói $\left(58.000 \mathrm{~m}^{3}\right)$ o segundo em 2015 e o da Praça Varnhagen $\left(43.000 \mathrm{~m}^{3}\right) \mathrm{em}$ 2016, totalizando $119.000 \mathrm{~m}^{3}$, menos da metade do planejado inicialmente.

Após a conclusão dos 3 reservatórios, e sem alteração aparente no regime de chuvas, a região continuou a ser afetada por inundações graves conforme as Figuras 1, 2 e 3, trazendo a percepção popular de que os projetos teriam sido insuficientes para a região.

Figura 1: Avenida Maracanã.

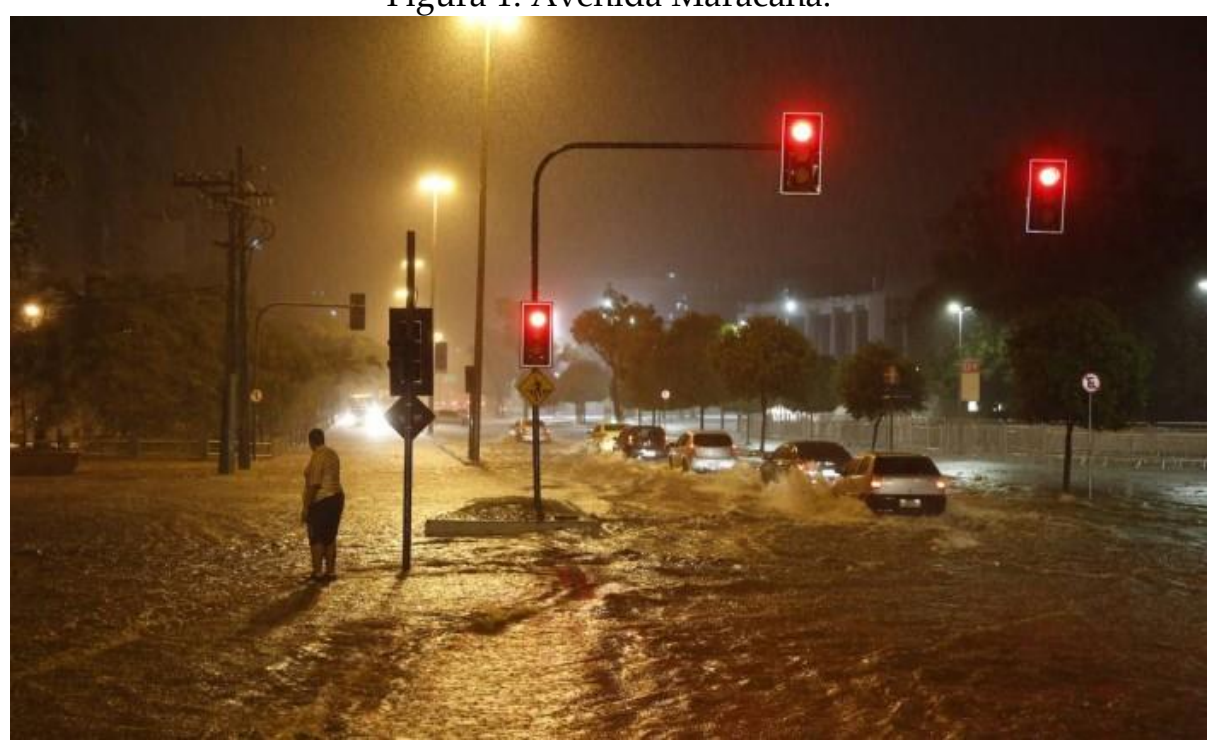

Fonte: Jornal “O Globo" (2017). 
Figura 2: Rio Joana na altura da Rua São Francisco Xavier.

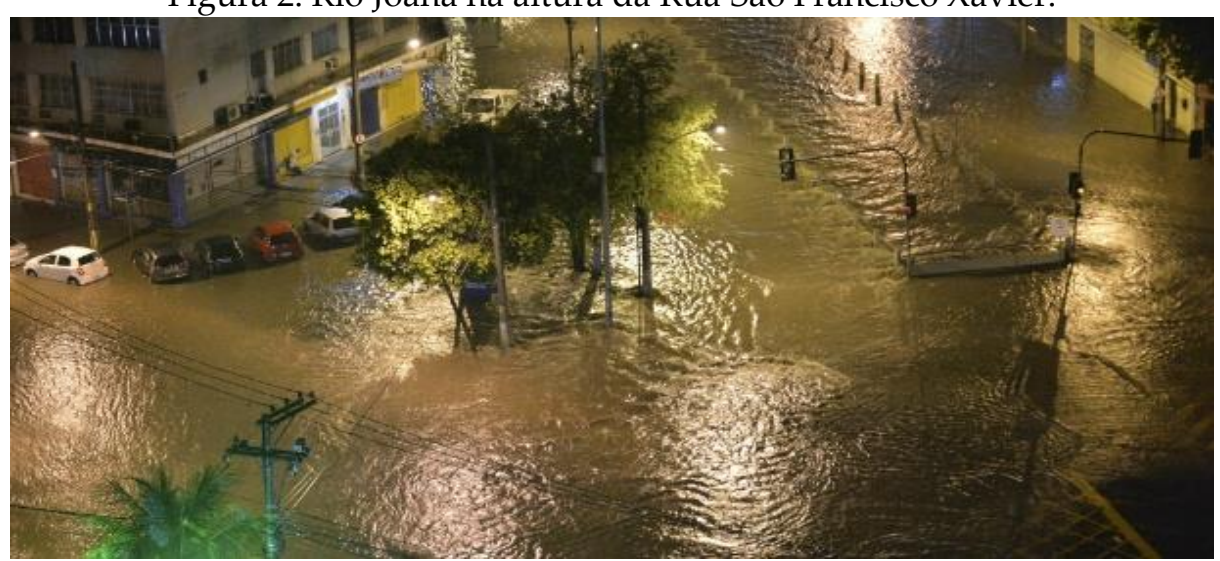

Fonte: Jornal “O Globo" (2018).

Figura 3: Rio Maracanã na altura do Shopping Tijuca.

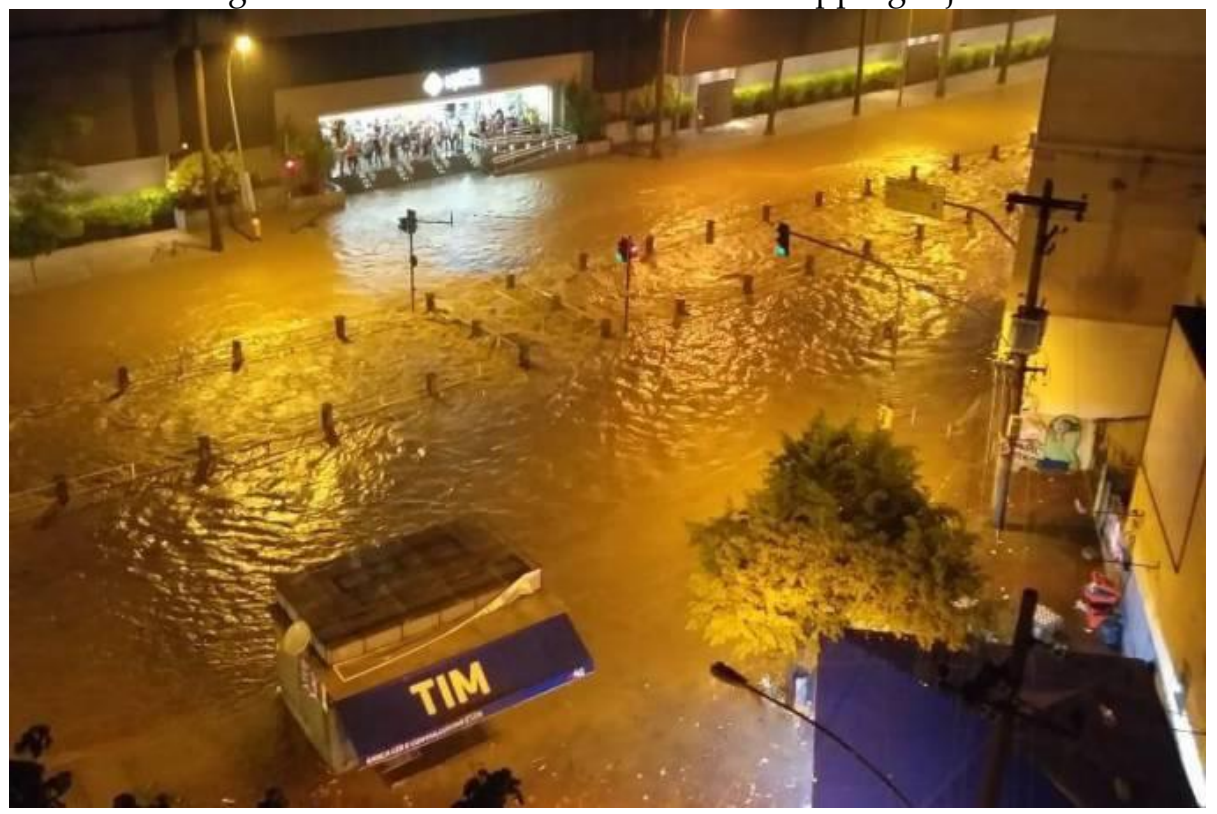

Fonte: Jornal Seropédica Online (2019).

\subsection{Caracterização da região}

Foi na primeira metade do século XIX, que começou a ser pensada uma forma de sanear a área do canal do Mangue, na região onde hoje situa-se o bairro da Cidade Nova no Centro do Rio de Janeiro, na época havia um imenso manguezal denominado Mangue de São Diogo.

A bacia do Canal do Mangue se caracteriza por uma área de drenagem com cerca de $45,4 \mathrm{~km}^{2}$, com limites ao norte com a sub-bacia do Canal do Cunha; a leste pela Baía da Guanabara e a sub-bacia do Centro. Ao Sul e a oeste o maciço da Tijuca. O sistema drena os bairros da Tijuca, Vila Isabel, Grajaú, São Cristóvão, Rio Comprido, Maracanã, Cidade Nova e Santo Cristo (ALERTA RIO, 2020). 
Os principais rios da bacia do Canal do Mangue são: Rios Maracanã, Joana, Trapicheiros, Comprido e PapaCouve, cujas nascentes estão no maciço da Tijuca ou na serra do Engenho Novo e correm para o Canal do Mangue que por sua vez deságua na Baía de Guanabara. Uma das características da bacia é a ocorrência de maciços baixos e morros isolados nas baixadas. A configuração da topografia acaba por não facilitar o escoamento das águas pluviais, ocasionando diversas inundações na região em dias de chuva mais intensa. Na Figura 4 é possível observar a localização das bacias hidrográficas no estado.

Figura 4: Bacias Hidrográficas da Cidade do Rio de Janeiro.

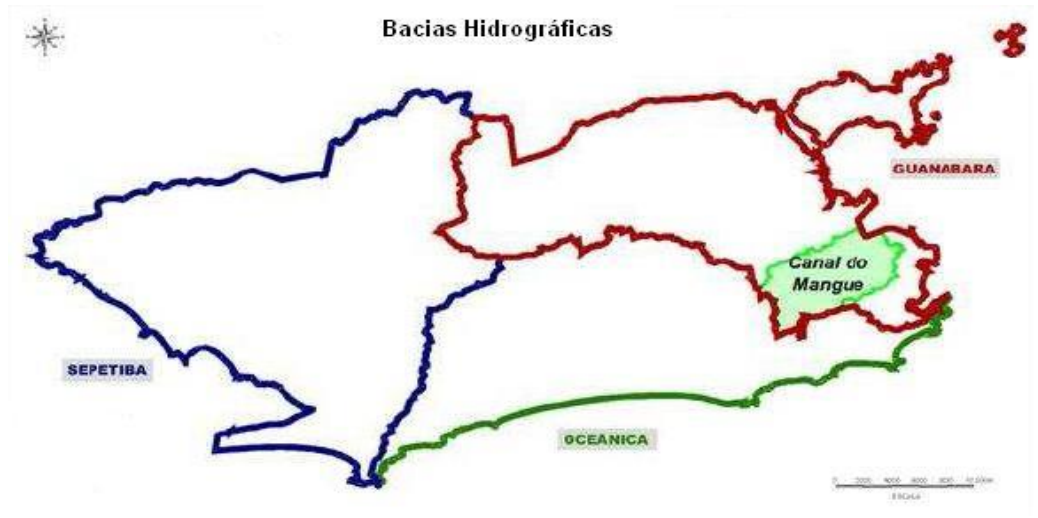

Fonte: PDMAP (2010).

\subsubsection{Obras contra cheias}

Em 2010 foi lançado o Plano Diretor de Manejo de Águas Pluviais (PDMAP) da Cidade do Rio de Janeiro. O plano previa uma série de intervenções na bacia hidrográfica no canal do mangue, dentre elas podemos destacar: Construção de reservatórios, desconcentração dos lançamentos, reforço nas canalizações existentes e adequação na capacidade de transporte dos canais.

O projeto lançado no PDMAP-2010 previa a construção de cinco reservatórios de detenção localizados: RJ3 - na cabeceira do Rio Joana, próximo ao Rio Jacó no alto Grajaú com capacidade para 50.000 m³ , RT-1 no Hipermercado Extra na Av. Heitor Beltrão com capacidade de $70.000 \mathrm{~m}^{3}$, RT-2 - Praça da Bandeira com capacidade de $18.000 \mathrm{~m}^{3}$, RM-1 Praça Varnhagen com $45.000 \mathrm{~m}^{3}$ com e RJ-4 praça Niterói com capacidade para $75.000 \mathrm{~m}^{3}$, como pode ser visto na Quadro 1, segundo o PDMAP.

\begin{tabular}{|c|c|c|c|c|c|c|c|c|}
\hline \multicolumn{9}{|c|}{ BACIA DO CANAL DO MANGUE } \\
\hline \multicolumn{9}{|c|}{ RESERVATÓRIOS } \\
\hline SIGLA & NOME & CURSO D'ÁGUA & ENDEREÇO & TIPO & $\begin{array}{l}\text { AREA DE } \\
\text { DRENAGEM } \\
\left.\text { TOTAL ( } \mathrm{m}^{2}\right)\end{array}$ & $\begin{array}{l}\text { ÁREA DE } \\
\text { DRENAGEM } \\
\text { PARCIAL }\left(m^{2}\right)\end{array}$ & $H(m)$ & $\begin{array}{l}\text { VOLUME } \\
\left(m^{2}\right)\end{array}$ \\
\hline RT-1 & Heitor Beltrão & Rio Trapicheiros & $\begin{array}{l}\text { Estacionamento do } \\
\text { Supermercado Extra, Av. Heitor } \\
\text { Beltrão, } 44\end{array}$ & $\begin{array}{l}\text { Off-Line, } \\
\text { Tamponado }\end{array}$ & 4,22 & 4,22 & 21,0 & 70.000 \\
\hline RT-2 & $\begin{array}{l}\text { Praça da } \\
\text { Bandeira }\end{array}$ & Rio Trapicheiros & Praça da Bandeira & $\begin{array}{l}\text { Off-Line, } \\
\text { Tamponado }\end{array}$ & 0,22 & 0,22 & 28,0 & 18.000 \\
\hline RJ-3 & Grajaú & Rio Joana & $\begin{array}{l}\text { Rua Borda do Mato x Rua } \\
\text { Mirandópolis }\end{array}$ & $\begin{array}{l}\text { Off-Line, } \\
\text { Aberto }\end{array}$ & 3,62 & 3,62 & 8,0 & 50.000 \\
\hline RJ-4 & Praça Niterói & Rio joana & Praça Niterói & $\begin{array}{l}\text { Off-Line, } \\
\text { Tamponado }\end{array}$ & 8.68 & 5,06 & 25,0 & 75.000 \\
\hline RM-1 & Praça Vamhagen & Rio Maracanã & Praça Vamhagen & $\begin{array}{l}\text { Off-Line, } \\
\text { Tamponado }\end{array}$ & 11,34 & 11,34 & 21,0 & 45.000 \\
\hline \multicolumn{8}{|c|}{ TOTAL RESERVATÓRIOS } & 258.000 \\
\hline
\end{tabular}

Fonte: PDMAP (2010). 


\subsection{Chuvas do Alerta Rio}

O Alerta Rio é o sistema de alerta de chuvas intensas e de deslizamentos em encostas da cidade do Rio de Janeiro. Foi criado em 25 de setembro de 1996 (Decreto No 15142) e desde então é gerenciado pela Fundação GEO-RIO, com o objetivo de emitir boletins de alerta à população sempre que houver previsão de chuvas intensas que possam gerar inundações de vias públicas e/ou acidentes geotécnicos em encostas (deslizamentos). Na Figura 5 observa-se a disposição das estações telepluviométricas no município do Rio de Janeiro.

Figura 5: Localização das 33 Estações Telepluviométricas do Sistema Alerta Rio no município do Rio de Janeiro e as 4 Estações estudadas.

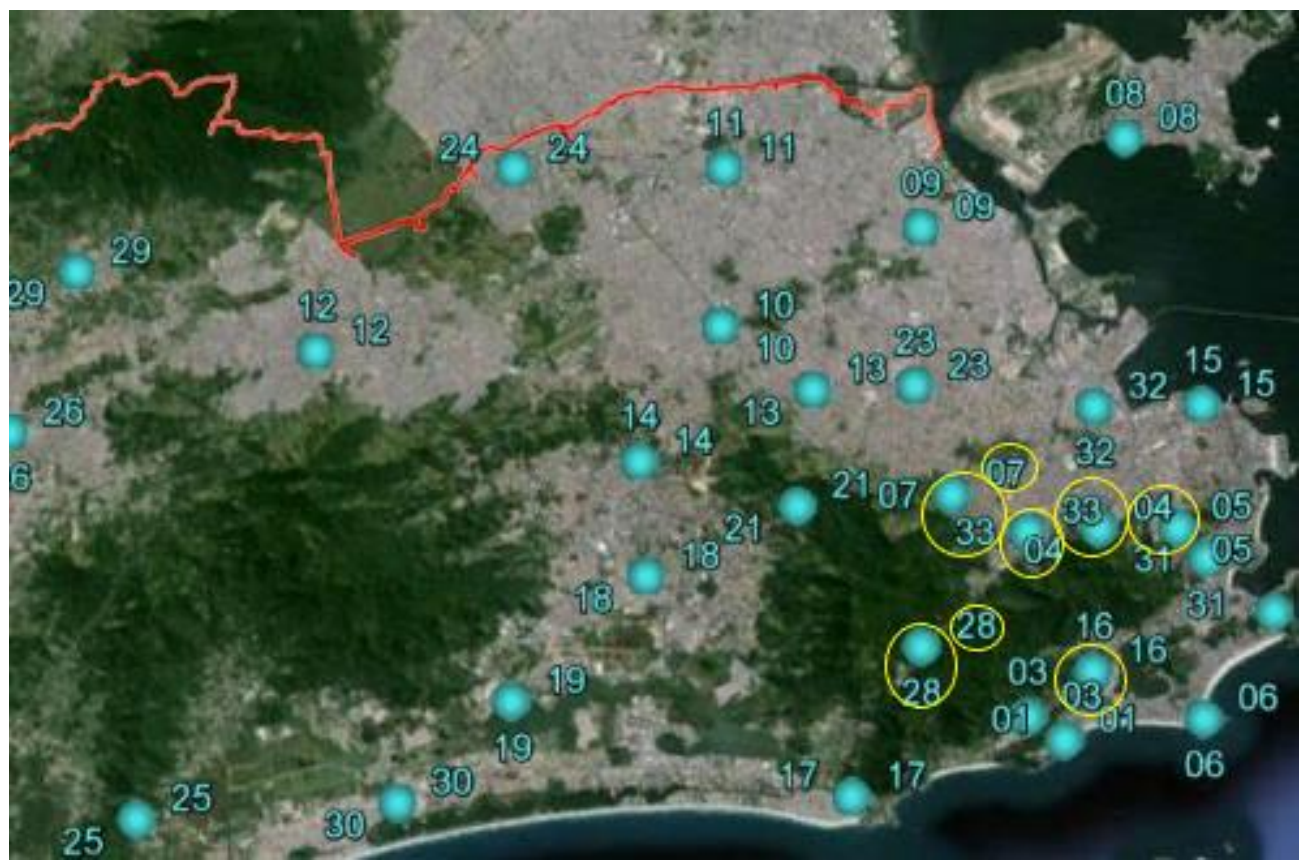

Fonte: Sistema Alerta Rio / Google Earth (2020).

Pode-se observar nas figuras a seguir diversas análises das estações da Tijuca, Grajaú, Alto da Boa Vista e Tijuca/Muda, a escolha das estações para análise foram baseadas nas suas localizações e área de contribuição para o Canal do Mangue.

Assim procurou-se ter informações sobre os acumulados pluviométricos anuais que mostram o volume de chuva em cada um dos quatro pontos escolhidos para análise, como pode ser visto pela Figura 6 não há um extremo em cada um dos quatro locais de medição que não tenha ocorrido em anos anteriores, o que nos faz perguntar qual outros fatores contribuem para as inundações além de chuvas fortes. Já as Figura 7 de máximas mensais mais críticas, Figura 8 de máxima em 24h ou e Figura 10 de máxima em chuvas de 1h, permitem que sejam realizadas uma completa leitura da contribuição das chuvas na bacia do Canal do Mangue, quanto a intensidade da chuva e períodos mais críticos para a bacia, como também a contribuição das chuvas para a ocorrência de inundações. 
Figura 6: Acumulado Pluviométrico.

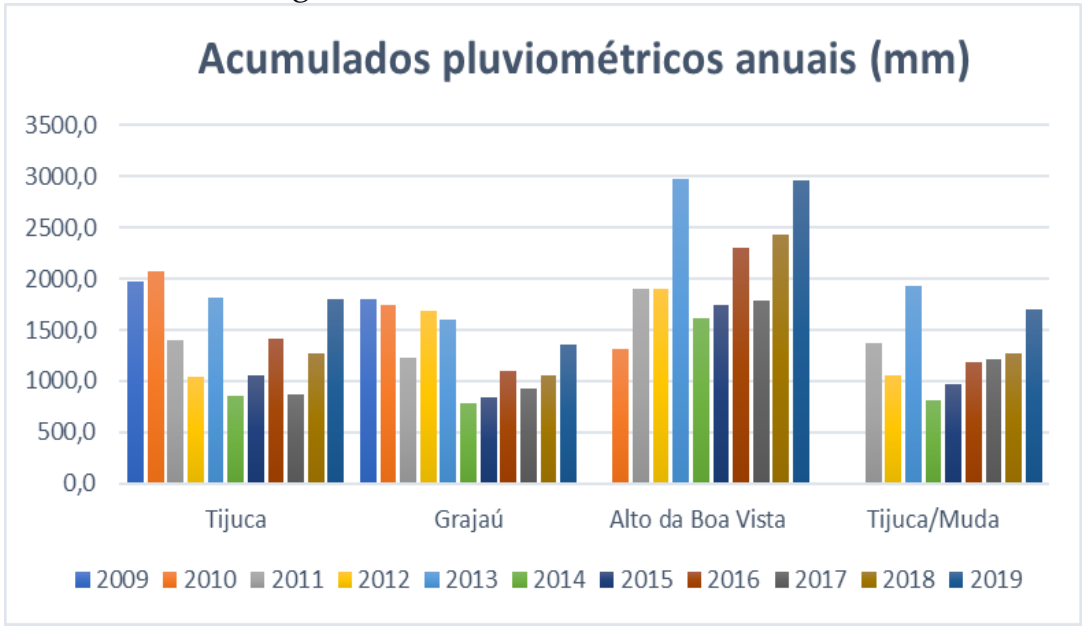

Fonte: Autores (2020).

Figura 7: Máximas Mensais.

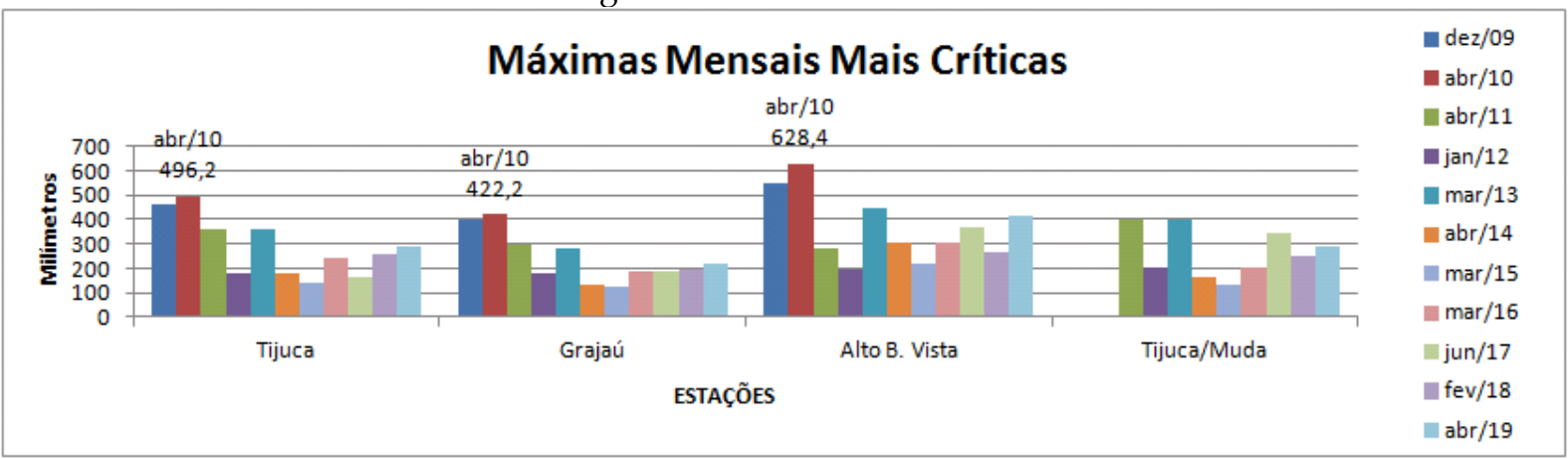

Fonte: Autores (2020).

Figura 8: Máximas de 24h.

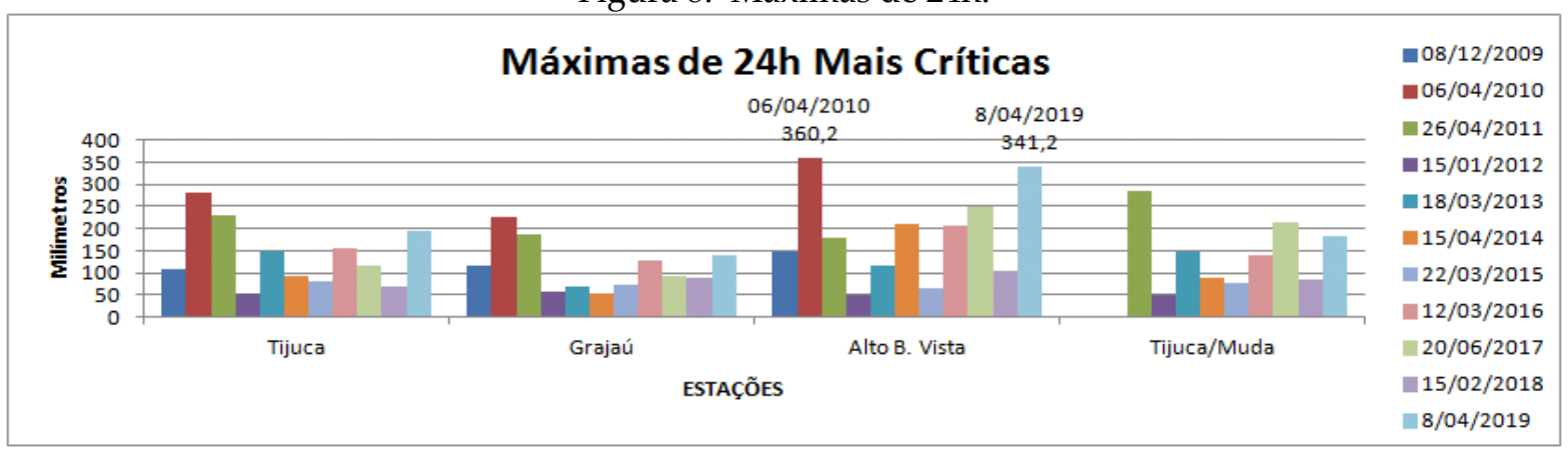

Fonte: Autores (2020). 
Figura 9: Máximas de 1h.

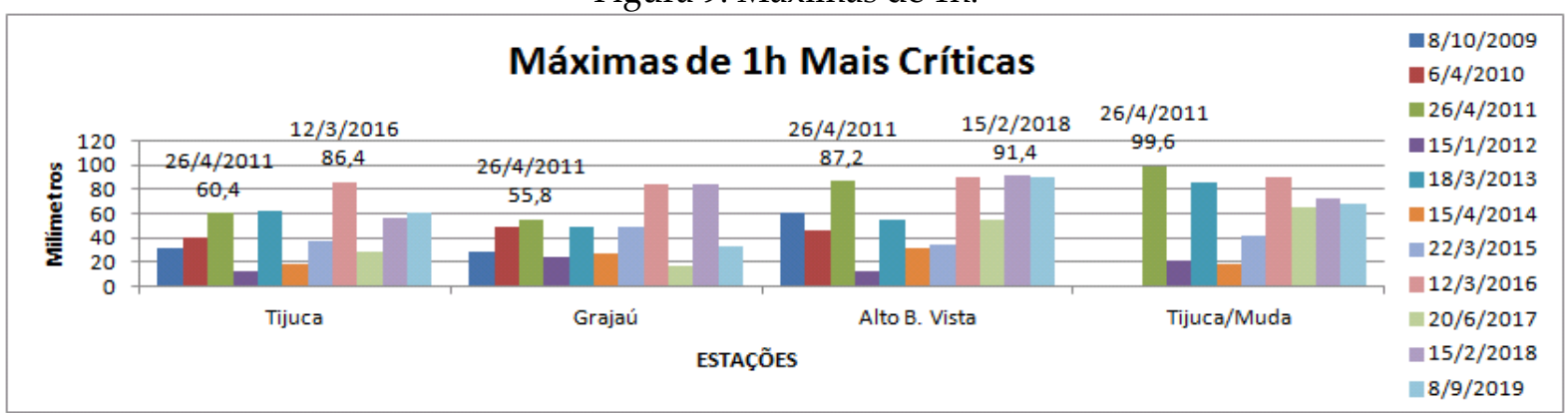

Fonte: Autores (2020).

Figura 10: Médias Mensais 1997-2018.

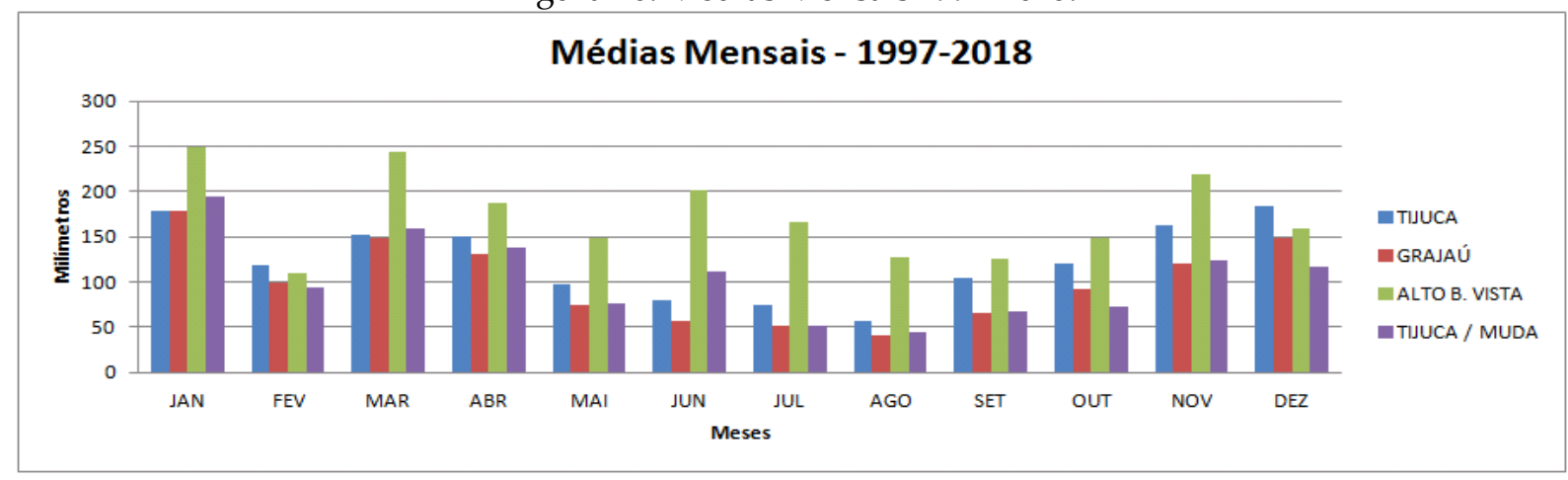

Fonte: Autores (2020).

As informações apresentadas acima, constroem um cenário como já mencionado anteriormente, de que não somente as chuvas intensas são responsáveis pelas já conhecidas inundações, que atingem a região da bacia do Canal do Mangue desde a década de 50 pois a região do Canal do Mangue, sofre a interferência de outros problemas já conhecidos pela população e poder público a longos anos que são a ocupação irregular das encostas/morros da região, urbanização sem planejamento da região, transformando a região em uma área predominantemente impermeável, lixo jogado e armazenado nas ruas e em locais irregulares provocando o entupimento das bocas de lobo quando ocorre chuvas fortes e a falta de manutenção do sistema de drenagem urbana e rios pelo poder público.

\subsection{Pesquisa sobre danos causados pela chuva}

São denominados eventos pluviométricos significativos aqueles que, dentre todos os eventos pluviométricos, são definidos segundo uma série de critérios pré-estabelecidos pela Fundação Geo-Rio, como portadores de um elevado potencial para deflagrar escorregamentos nas encostas. A instituição foi criada após os graves eventos chuvosos que castigaram o Rio de Janeiro em 1966, sob o impacto do forte temporal registrado em janeiro daquele ano. Na ocasião, a intensidade da chuva causou deslizamentos nas encostas de morros nas Zonas Sul e Norte, levando morte e destruição a comunidades carentes.

O órgão mantém, em parceria com a Defesa Civil do Município, um plantão permanente para socorro em caso de deslizamento de rochas ou de encostas. Além disso, desenvolve um trabalho preventivo, pela vistoria periódica de locais de risco e pela distribuição de folhetos que ensinam moradores a evitar acidentes causados por escavações e pelo acúmulo de resíduos nas encostas. Devido seu grande conhecimento e longo 
tempo de dedicação a mitigação dos impactos causados pelas chuvas a Geo-Rio se tornou precursora no assunto em questão.

\subsection{Análise das marés e erosão}

De acordo com a Figura 11, observa-se as regiões do município do Rio de Janeiro, vulneráveis à elevação do nível do mar, e com dados projetados até 2080 as localidades em vermelho estão sujeitas a marés de até $96 \mathrm{~cm}$, as em amarelo estão sujeitas a marés de até $144 \mathrm{~cm}$ e as beges que estão sujeitas a 177cm (GEO-RIO, 2020), assim podemos concluir que a região do Canal do Mangue não é vulnerável às alterações das marés de forma direta, contudo, após a realização da obra do Piscinão da Praça da Bandeira levantou-se a preocupação de ela ser indiretamente afetada com as mudanças do nível do mar, devido ao fato de que as águas captadas no piscinão são lançadas na Baía de Guanabara pelo Rio Joana, esta visualização pode ser vista no mapa da Figura 4.

No entanto, apesar do projeto pronto, certos fatores na área fora a maré contribuem como pontos negativos para o funcionamento pleno do Piscinão da Praça da Bandeira que é o assoreamento e erosão que vêm ocorrendo na região do Porto da cidade do Rio de Janeiro (Prefeitura do Rio de Janeiro, 2020), esse evento não só altera o calado dos navios que procuram o Porto do Rio de Janeiro, mas também provoca indiretamente a criação de barreiras que podem tanto obstruir o lançamento de novos rejeitos vindo da Praça da Bandeira, elevar o nível do mar ou provocar a obstrução completa da tubulação de despejo na Baía.

Figura 11 - Mapas de áreas vulneráveis à elevação do nível do mar.

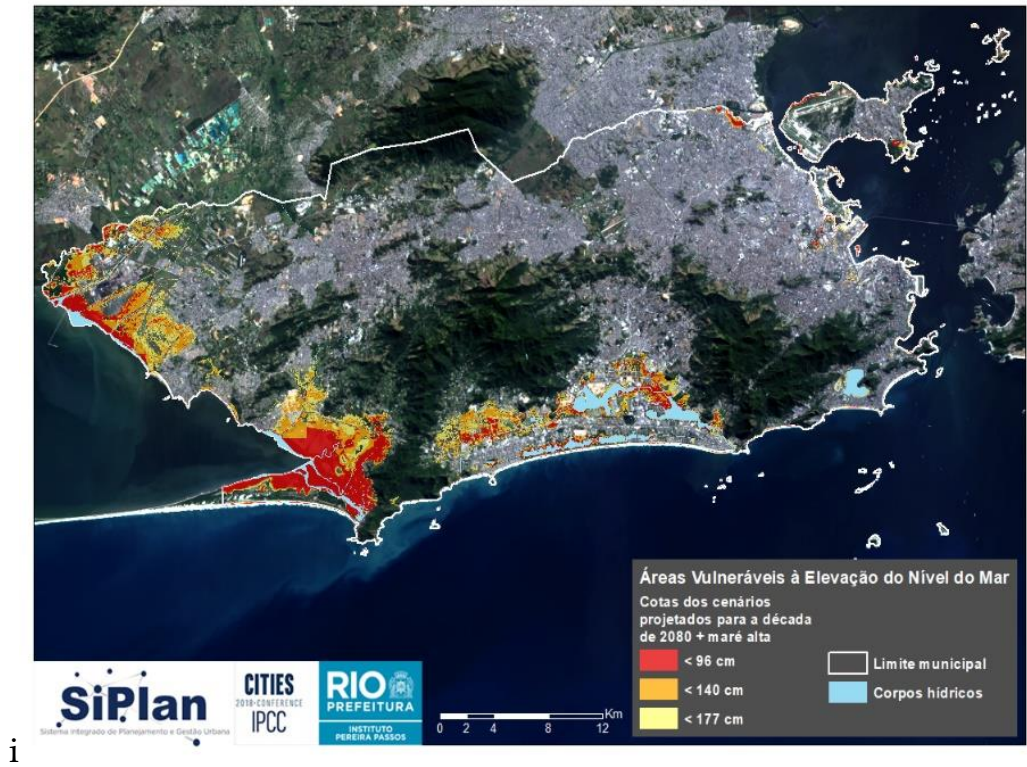

Fonte: SiPlan (2020).

\section{CONCLUSÕES}

Após os estudos realizados conclui-se que dados pluviométricos no período analisado não apresentaram variação no tempo de recorrência. Porém, comparando-se as médias dos últimos anos com períodos mais longos é possível identificar chuvas mais intensas nos últimos períodos, mas que não são, sob nenhum aspecto, atípicas. Este aspecto leva à conclusão de que o regime de chuvas na área da bacia não sofreu 
nenhuma alteração relevante a ponto de mudar as características hidrológicas do local. O crescimento populacional e o adensamento urbano, especialmente com ocupações irregulares do Maciço da Tijuca, ocorrido na segunda metade do século XX também contribuíram substancialmente para aumentar a frequência das inundações, uma vez que expandiu a área de solo impermeabilizado e passou a injetar nos canais volumes cada vez maiores de sedimentos oriundos da erosão das encostas.

Alguns pontos em relação ao PCEGT chamam atenção. A obra do desvio do Rio Joana foi finalizada em 2019 e desde sua conclusão não ocorreu nenhuma chuva de intensidade que demande a capacidade plena do sistema de forma a testá-lo. Além disso, o reservatório RT-1, na Avenida Heitor Beltrão, projetado para amortecer a vazão) do Rio Trapicheiros, não foi construído e não há consenso sobre a viabilidade ou a efetividade de implantá-lo conforme o plano original. Após análise, é possível constatar que a Bacia do Canal do Mangue continua sendo um local de alto risco de inundações, mesmo tendo passado por intervenções com o intuito de controlar o problema. Vale ressaltar que não houve descarte na opção de intervenções futuras, visto que melhorias e adaptações do sistema são bem vistas.

\section{REFERÊNCIAS}

ALERTA RIO "Sistema Alerta Rio da Prefeitura do Rio de Janeiro - Relatórios Pluviométricos Anuais". Disponível em: $<$ https://alertario.rio.rj.br/>. Acessado em: 21 de Dezembro de 2020.

CANHOLI, A. P., GRACIOSA, M. C. P. "Enchentes Na Cidade Do Rio De Janeiro - Causas E Soluções Estudo De Caso: Bacia Do Canal Do Mangue". 2011. Anais [...] [S.l: s.n.], 2011.

COIMBRA, A.L. Lessons of Continuum Mechanics, Ed. Edgard Blücher, São Paulo, Brasil, 1978, 428 p.

CLARK, J.A. Private Communication, Universidade de Michigan, Ann Harbor, 1986. Hidrostudio-FCTH / Rio-Águas (2010) - Plano Diretor de Manejo de Águas Pluviais da Cidade do Rio de Janeiro PDMAP - RJ.

DERECZYNSKI, C. P., CALADO, R. N., DE BARROS, A. B. "Chuvas Extremas no Município do Rio de Janeiro: Histórico a partir do Século XIX", Anuário do Instituto de Geociências, v. 40, n. 2, p. 17-30, 2017. DOI: 10.11137/2017_2_17_30.

D'ÓRCI R. N. et. al. “Relatório Anual de Chuva para a cidade do Rio de Janeiro no ano de 2015”. Relatório GEO-RIO/DEP/GPE - N. 001/2016. Prefeitura da Cidade do Rio de Janeiro. 2016.

FUNDAÇÃO INSTITUTO DE GEOTÉCNICA DO MUNICÍPIO DO RIO DE JANEIRO, GEO-RIO Disponível em: < www.rio.rj.gov.br/web/georio/quem-somos>. Acessado em 21 de Dezembro de 2020.

IBGE. Distribuição da população. Rio de Janeiro, 2018. Disponível em: https://atlasescolar.ibge.gov.br/images/atlas/mapas_brasil/brasil_distribuicao_populacao.pdf

JOYCE, J., CHANG, N. Bin, HARJI, R., et al. "Developing a multi-scale modeling system for resilience assessment of green-grey drainage infrastructures under climate change and sea level rise impact", Environmental Modelling and Software, v. 90, p. 1-26, 2017. DOI: 10.1016/j.envsoft.2016.11.026. Disponível em: http://dx.doi.org/10.1016/j.envsoft.2016.11.026.

LUCENA, F. História do canal do Mangue, O diário do Rio. 2018. Disponível em: $<$ https://diariodorio.com/historia-do-canal-do-mangue>. Acessado em: 21 de Dezembro de 2020. 
PLANO DIRETOR RIO 2020. Disponível em: < https://plano-diretor-pcrj.hub.arcgis.com/>. Acessado em: 22 de Dezembro de 2020.

RIO-ÁGUAS. Fundação Instituto das Águas do Município do Rio de Janeiro. Disponível em: $<$ http://www.pcrj.rj.gov.br/web/rio-aguas/exibeconteudo?id=9541042>. Acessado em: 22 de Dezembro de 2020. 